\title{
Cem Anos de Imigração Japonesa no Brasil. Lições Sociometabólicas
}

$\mathrm{P}$ ORTO De SANTOS (SP), manhã do dia 18 de junho de 1908.

Chega ao Brasil o navio Kasato Maru, trazendo a bordo os primeiros 781 japoneses que vieram trabalhar na lavoura cafeeira do Estado de São Paulo (1). No final do século XIX, com o fim do feudalismo, início da mecanização da lavoura e a presença de uma crise demográfica, a pobreza passou a assolar o campo formando uma massa de trabalhadores rurais miseráveis que viram, na emigração para o Brasil, uma esperança de riqueza (Figura 1). Foram 50 dias cruzando os oceanos Pacífico e Índico, e após cruzarem o Cabo da Boa Esperança chegaram ao Brasil.

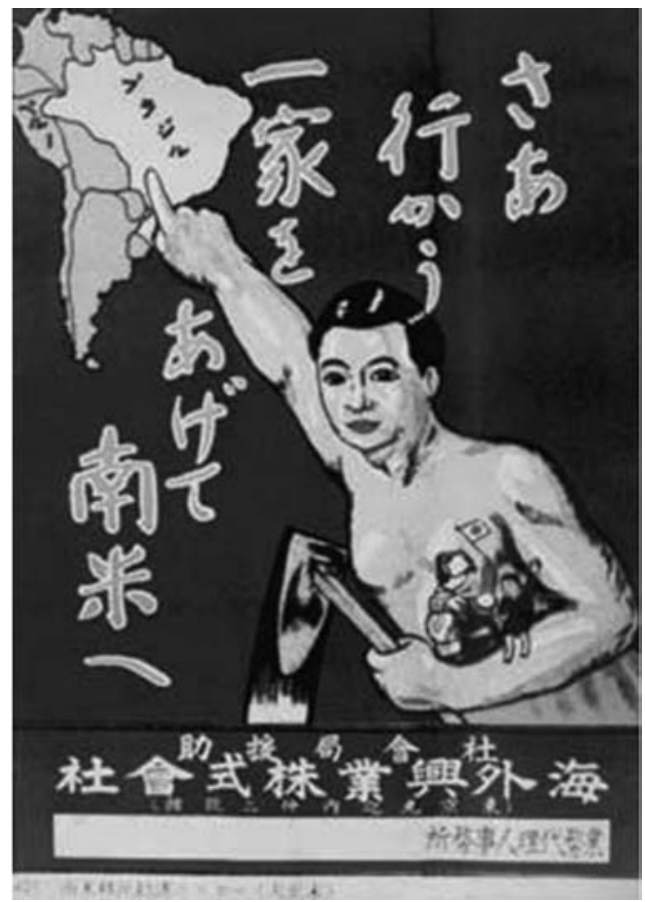

Figura 1. Cartaz japonês do início do século XX, estimulando a emigração para o Brasil

Podemos imaginar que ondas de fome e pobreza puderam expor a população japonesa ao fenômeno de seleção de genes poupadores (thifty genes), bem como aumentaram os índices de nascimento de crianças de baixo peso, o que contribuiria para um maior risco de doenças metabólicas, conforme descrito em diversas populações $(2,3)$.

Uma carta, enviada pelo cônsul brasileiro no Japão, no início do século $\mathrm{XX}$, analisava criticamente os emigrados, considerando-os limitados fisicamente e recomendava que não se devesse exigir deles mais do que dois terços da produção de um europeu, e que os salários deveriam ser proporcionais a

\section{editorial}

\section{Bruno Geloneze \\ ADEMAR Yamanaka}

Coordenador do Laboratório de Investigação em Metabolismo e Diabetes (LIMED) do Centro de Diagnóstico de Doenças do Aparelho Digestivo (Gastrocentro) da Universidade Estadual de Campinas (Unicamp), Campinas, SP, Brasil (BG);

Professor do Departamento Clínica Médica e Coordenador Geral do Gastrocentro da Unicamp, Campinas, SP, Brasil (AY) 
esta diferença de produtividade. Havia uma ressalva aos procedentes da ilha de Okinawa, no sul do Japão, que lhe pareciam fortes, resistentes e muito dados à agricultura (1). Atualmente, a ilha de Okinawa tem uma das maiores prevalências de diabetes no Japão, com 9,2\% dos homens e 7,5\% das mulheres afetados pela doença, o que constitui o dobro da prevalência de 15 anos atrás naquela região (4). Este fenômeno tem relação direta com recentes mudanças de hábito de vida, exemplificada pelo aumento de supermercados para os quais esta população cada vez mais se desloca de automóvel (5). Em Bauru, Estado de São Paulo, das cerca de 2.300 famílias de descendentes de japoneses, a maioria é proveniente da ilha de Okinawa e se concentra nos bairros de Vila Independência e Vila Nipônica (6). Estes, mais recentemente, abandonaram a lavoura e novamente migraram, agora para a cidade, sendo mais fortemente influenciados pelo estilo de vida ocidental. O grupo de pesquisadores do Japanese-Brazilian Diabetes Study Group (JBDSG) vem estudando esta população e indicam crescentes índices de doenças metabólicas (7), maior presença de doença macrovascular (8), que em parte são relacionados a mudanças dietéticas que incluem maior consumo de gordura, em especial na sua forma trans (9), mas não estão relacionados a possíveis alterações na autoimunidade (10). Nesta edição dos ABE\&M, Siqueira e cols. do JBDSG apresentam dados alarmantes sobre a prevalência de dislipidemia na população nipo-brasileira de Bauru (11). Neste trabalho, os autores mostram colesterol total médio de $214 \mathrm{mg} / \mathrm{dL}$ para esta população. Se considerarmos os dados da população japonesa estudada pela Japan Atherosclerosis Society (JAS) isto implicaria em risco adicional de $40 \%$ para a ocorrência de doença arterial coronariana (12).

Atualmente vivem no Japão mais de 300 mil brasileiros, a maioria dos quais é brasileira de origem japonesa, conhecidos como Dekassegui, em busca de melhores oportunidades de trabalho, como fizeram seus ascendentes, mas agora em fluxo inverso. A comunidade brasileira no Japão é a terceira maior de brasileiros fora do Brasil e também, é a terceira maior comunidade imigrante no Japão, atrás apenas dos coreanos e chineses. Por outro lado, a comunidade japonesa brasileira é a maior do mundo fora do Japão. Pesquisadores da Universidade de Tsukuba, no Japão, estudaram a presença de obesidade central e doenças relacionadas em japoneses nativos comparando-os com brasileiros de origem japonesa residindo no Brasil e no Japão (13). Entre os brasileiros de origem japonesa residindo no Brasil, o risco de obesida- de central é 2,8 vezes maior do que os residentes no Japão. Esta associação, no entanto, não se mantém após ajustes para fatores dietéticos e nível de sedentarismo. Este achado reforça a importância do estilo de vida como determinante do risco metabólico pelo acúmulo de gordura visceral. Em estudo da população norteamericana de origem japonesa, Kahn e colaboradores demonstraram que o aumento de 1 desvio-padrão na quantidade de gordura visceral avaliada por tomografia computadorizada, prediz o aparecimento de síndrome metabólica, com um odds ratio de 2,08 em uma população não-obesa (14). Por outro lado, em estudo realizado no Japão, durante o seguimento de um ano, a redução de apenas $3 \mathrm{~cm}$ na circunferência abdominal pode melhorar, ou reverter, a síndrome metabólica e seus componentes (15).

Dados semelhantes aos encontrados nos nipo-brasileiros de Bauru foram observados nos nipo-norteamericanos residentes na Califórnia e no Havaí (2). Mais recentemente, no Japão, as crianças em idade escolar passaram a apresentar pequenos ganhos de peso, mas com significativo impacto deletério sobre a resistência à insulina e sobre o perfil lipídico (16). Estes dados, em conjunto, reforçam a importância do estilo de vida sedentário e da dieta tóxica como fatores obesodiabetogênicos, e por fim, aterogênicos. O que se espera é que exemplos como o da população japonesa despertem a humanidade para enfrentar o desafio do encontro salutar entre a vida moderna e um estilo de vida saudável.

Que no próximo centenário da imigração japonesa no Brasil estejamos mais desenvolvidos, integrados, democráticos e, quem sabe, mais saudáveis.

\section{REFERÊNCIAS}

1. A imigração japonesa no Brasil. Edição especial do Jornal Nippo-Brasil 2005; p.6.

2. Simmons R. Developmental origins of adult metabolic disease: concepts and controversies. Trends Endocrinol Metab. 2006;16:390-4.

3. Paradies YC, Montoya MJ, Fullerton SM. Racialized genetics and the study of complex diseases: the thrifty genotype revisited. Perspec Biol Med. 2007;50:203-27.

4. Tanaka H, Shimabukuro T, Shimabukuro M. High prevalence of metabolic syndrome among men in Okinawa. J Atheroscler Thromb. 2005;12:284-8.

5. Takasu N, Yogi H, Takara M, Higa M, Kouki T, Ohshiro Y et al. Influence of motorization and supermarket-proliferation on the prevalence of type 2 diabetes in the inhabitants of a small town on Okinawa, Japan. Intern Med. 2007;.46:1899-904. 
6. Camargo A. Japoneses estão em Bauru há 94 anos. Jornal da Cidade de Bauru 2008, Disponível em: http://www.jcnet.com. br/editorias/detalhe_agencias.php?codigo $=121233$

7. Ferreira SR, Lerario DD, Gimeno SG, Sanudo A, Franco LJ Japanese-Brazilian Diabetes Study Group. Prevalence and 7-year incidence of Type II diabetes mellitus in a JapaneseBrazilian population: an alarming public health problem. $J$ Epidemiol. 2002;12:431-8.

8. Siqueira A, Franco LJ, Gimeno SG, Matsumura L, Abdalla D, de Barros Jr N, Ferreira SR. Macrovascular disease in a Japanese-Brazilian population of high prevalence of metabolic syndrome: associations with classical and non-classical risk factors. Atherosclerosis. 2007;195:160-6.

9. Bertolino CN, Castro TG, Sartorelli DS, Ferreira SR, Cardoso MA, Grupo de Estudos de Diabetes em Nipo-brasileiros. Dietary trans fatty acid intake and serum lipid profile in Japanese-Brazilians in Bauru, São Paulo, Brazil. Cad Saúde Pública. 2006;22:357-64.

10. Hashimoto SM, Gimeno SG, Matsumura L, Franco LJ, Miranda WL, Ferreira SR, Japanese-Brazilian Diabetes Study Group. Autoimmunity does not contribute to the highly prevalent glucose metabolism disturbances in a Japanese Brazilian population. Ethn Dis. 2007;17:78-83.

11. Siqueira AFA, Harima HA, Osiro K, Hirai AT, Gimeno SGA, Ferreira SRG, Japanese-Brazilian Diabetes Study Group. Distúrbios no perfil lipídico são altamente prevalentes em população nipo-brasileira. Arq Bras Endocrinol Metal. 2008; 52:40-46

12. Teramoto T, Sasaki J, Ueshima H, Egusa G, Kinoshita M, Shimamoto $\mathrm{K}$ et al. Risk factors of atherosclerotic diseases. Executive summary of Japan Atherosclerosis Society (JAS) guideline for diagnosis and prevention of atherosclerosis cardiovascular diseases for Japanese. J Atheroscler Thromb. 2007;14:267-77.

13. Schwingel A, Nakata Y, Ito LS, Chodzko-Zajko WJ, Shigematsu $\mathrm{R}$, Erb CT et al. A comparison of the prevalence of the metabolic syndrome and its components among native Japanese and Japanese Brazilians residing in Japan and Brazil. Eur J Cardiovasc Prev Rehabil. 2007;14:508-14.

14. Tong J, Boyko EJ, Utzschneider KM, McNeely MJ, Hayashi T, Carr DB et al. Intra-abdominal fat accumulation predicts the development of the metabolic syndrome in non-diabetic Japanese-Americans. Diabetologia. 2007;50:1156-60

15. Miyatake N, Matsumoto S, Fujii M, Numata T. Reducing waist circumference by at least $3 \mathrm{~cm}$ is recommended for improving metabolic syndrome in obese Japanese men. Diabetes Res Clin Pract. 2007 Oct 22; [Epub ahead of print].

16. Asato $Y$, Katsuren K, Ohshiro T, Kikawa K, Shimabukuro T, Ohta T. Relationship between lipid abnormalities and insulin resistance in Japanese school children. Arterioscler Thromb Vasc Biol. 2006;26:2781-6.

\section{Endereço para correspondência:}

Bruno Geloneze

Rua Camargo Paes 251,

13073-350 Campinas, SP

bgeloneze@terra.com.br 